\title{
Proteasome 26S subunit, non-ATPases 1 (PSMD1) and 3 (PSMD3), play an oncogenic role in chronic myeloid leukemia by stabilizing nuclear factor-kappa B
}

\author{
Alfonso E. Bencomo-Alvarez ${ }^{1} \cdot$ Andres J. Rubio $^{1} \cdot$ Idaly M. Olivas $^{2} \cdot$ Mayra A. Gonzalez $^{1} \cdot$ Rebecca Ellwood $^{3}$. \\ Carme Ripoll Fiol $^{3}$ - Christopher A. Eide ${ }^{4}$. Joshua J. Lara ${ }^{1}$. Christian Barreto-Vargas ${ }^{5} \cdot$ Luis F. Jave-Suarez $^{6}$. \\ Georgios Nteliopoulos $^{3,7}$ - Alistair G. Reid ${ }^{8}$. Dragana Milojkovic ${ }^{3}$ - Brian J. Druker $\mathbb{1}^{4} \cdot$ Jane Apperley $^{3}$. \\ Jamshid S. Khorashad ${ }^{3}$ Anna M. Eiring $\mathbb{1}^{1,2}$
}

Received: 22 September 2020 / Revised: 19 February 2021 / Accepted: 23 February 2021 / Published online: 12 March 2021

(c) The Author(s) 2021. This article is published with open access

\begin{abstract}
Tyrosine kinase inhibitors (TKIs) targeting BCR-ABL1 have revolutionized therapy for chronic myeloid leukemia (CML), paving the way for clinical development in other diseases. Despite success, targeting leukemic stem cells and overcoming drug resistance remain challenges for curative cancer therapy. To identify drivers of kinase-independent TKI resistance in CML, we performed genome-wide expression analyses on TKI-resistant versus sensitive CML cell lines, revealing a nuclear factor-kappa B (NF-KB) expression signature. Nucleocytoplasmic fractionation and luciferase reporter assays confirmed increased NF- $\mathrm{KB}$ activity in the nucleus of TKI-resistant versus sensitive CML cell lines and CD34 $4^{+}$patient samples. Two genes that were upregulated in TKI-resistant CML cells were proteasome 26S subunit, non-ATPases 1 (PSMD1) and 3 (PSMD3), both members of the $19 \mathrm{~S}$ regulatory complex in the $26 \mathrm{~S}$ proteasome. PSMD1 and PSMD3 were also identified as survival-critical genes in a published small hairpin RNA library screen of TKI resistance. We observed markedly higher levels of PSMD1 and PSMD3 mRNA in CML patients who had progressed to the blast phase compared with the chronic phase of the disease. Knockdown of PSMD1 or PSMD3 protein correlated with reduced survival and increased apoptosis in CML cells, but not in normal cord blood $\mathrm{CD} 34^{+}$progenitors. Luciferase reporter assays and immunoblot analyses demonstrated that PSMD1 and PSMD3 promote NF- $\mathrm{KB}$ protein expression in CML, and that signal transducer and activator of transcription 3 (STAT3) further activates NF- $\kappa B$ in scenarios of TKI resistance. Our data identify NF- $\mathrm{BB}$ as a transcriptional driver in TKI resistance, and implicate PSMD1 and PSMD3 as plausible therapeutic targets worthy of future investigation in CML and possibly other malignancies.
\end{abstract}

Supplementary information The online version contains supplementary material available at https://doi.org/10.1038/s41388021-01732-6.

Anna M. Eiring

anna.eiring@ttuhsc.edu

1 Center of Emphasis in Cancer, Department of Molecular and Translational Medicine, Paul L. Foster School of Medicine, Texas Tech University Health Sciences Center El Paso, El Paso, TX, USA

2 Graduate School of Biomedical Sciences, Texas Tech University Health Sciences Center El Paso, El Paso, TX, USA

3 Centre for Haematology, Department of Medicine, Imperial College London, London, UK

\section{Introduction}

Chronic myeloid leukemia (CML) is a malignancy of the pluripotent hematopoietic stem cell, in which a reciprocal translocation between chromosomes 9 and 22 produces

4 Knight Cancer Institute, Division of Hematology/Medical Oncology, Oregon Health \& Science University, Portland, OR, USA

5 Universidad de Guadalajara, Guadalajara, Jalisco, México

6 Instituto Mexicano del Seguro Social, Centro de Investigación Biomédica de Occidente, Guadalajara, Jalisco, México

7 Department of Surgery and Cancer, Imperial College London, London, UK

8 Molecular Pathology Unit, Liverpool Clinical Laboratories, Royal Liverpool University Hospital, Liverpool, UK 
BCR-ABL1, the oncogenic tyrosine kinase that drives disease [1]. In newly diagnosed CML patients, tyrosine kinase inhibitors (TKIs) targeting BCR-ABL1 are remarkably effective at eliminating most $B C R-A B L 1-$ positive cells, especially in the chronic phase (CP-CML) $[2,3]$. However, TKIs do not eliminate CML leukemic stem cells (LSCs) [4-7], and while some studies have reported treatment-free remission following deep molecular response [8-10], life-long therapy is required to maintain remission in most patients $[11,12]$. Long-term TKI treatment is associated with a high economic burden and a reduced quality of life, including adverse cardiovascular events [13-16] and skeletal muscle toxicity [17]. Additionally, patients who progress to the blast phase of CML (BP-CML) still have a poor prognosis [2, 3]. Understanding the mechanisms driving TKI resistance will inform treatment strategies aimed at curing the disease.

TKI resistance is often linked to point mutations in the BCR-ABL1 kinase domain that impair drug binding [18]. However, many cases of clinical resistance occur in the absence of $B C R-A B L 1$ mutations [3]. BCR-ABL1-independent resistance is a feature of the CML LSC population, providing a reservoir of cells for disease recurrence via mechanisms that are not well understood [5, 6, 19]. Our previous work demonstrated that CML stem and progenitor cells that are TKI-resistant, but lack explanatory BCR-ABL1 kinase domain mutations, are dependent on the activation of alternative signaling pathways, especially signal transducer and activator of transcription 3 (STAT3) [19-21]. To better understand the transcriptional drivers of TKI resistance, we performed genome-wide expression analyses on TKI-resistant CML cells versus parental controls using RNA sequencing (RNA-seq). Analysis of this data set implicated nuclear factor-kappa B $(\mathrm{NF}-\kappa \mathrm{B})$ as the transcriptional driver of TKI resistance. NF- $\kappa \mathrm{B}$ is known to regulate the expression of diverse gene targets in many different cancers, including CML [22-24].

The ubiquitin-proteasome system (UPS) plays an important role in activating and terminating NF- $\mathrm{NB}$ signaling in many different scenarios $[25,26]$. Interestingly, two members of the UPS, proteasome 26S subunit, nonATPases 1 (PSMD1) and 3 (PSMD3), were upregulated in TKI-resistant CML cell lines and patient samples $[27,28]$. They were also identified as survival-critical genes in a previously published small hairpin RNA (shRNA) library screen for TKI resistance [29]. PSMD1 and PSMD3 are members of the 19S regulatory complex in the $26 \mathrm{~S}$ proteasome, regulating substrate recognition and binding [30, 31]. In breast cancer, PSMD1 promoted cancer cell growth by inducing p53 protein degradation [30]; PSMD3, in contrast, enhanced cancer cell growth by stabilizing human epidermal growth factor receptor 2 (HER2) from degradation [31]. In acute myeloid leukemia (AML), patients with higher levels of PSMD3 mRNA were shown to have a worse overall survival than patients with lower levels of expression [32]. In the present study, we hypothesized that PSMD1 and PSMD3 mediate $\mathrm{NF}-\kappa \mathrm{B}$ activation in CML and TKI resistance. Here, we report that PSMD1 and PSMD3 promote NF- $\kappa \mathrm{B}$ protein expression and transcriptional activity in CML, and that STAT3 perpetuates this signal in scenarios of TKI resistance. Our data implicate PSMD1 and PSMD3 as potential targets for combination therapies in myeloid malignancies and possibly other cancers.

\section{Results}

\section{The transcriptional signature of TKI resistance is reminiscent of tumor necrosis factor alpha (TNFa) signaling via NF-KB}

To investigate potential drivers of BCR-ABL1 kinaseindependent TKI resistance, we performed RNA-seq on extracts from TKI-resistant $\mathrm{K} 562^{\mathrm{R}}$ cells versus parental, TKI-sensitive $\mathrm{K} 562^{\mathrm{S}}$ controls. $\mathrm{K} 562^{\mathrm{R}}$ cells are an in vitro model of BCR-ABL1-independent TKI resistance, which lack explanatory $B C R-A B L 1$ kinase domain mutations and survive despite TKI-mediated BCR-ABL1 inhibition [19, 21]. An MA plot was produced from DESeq2 to visualize the data (Supplementary Fig. S1A), and Euclidean distance calculations demonstrated clear separation between the two cell lines (Supplementary Fig. S1B). Gene set enrichment analysis (GSEA) [22-24] on the differentially expressed genes implicated $\mathrm{TNF} \alpha$ signaling via $\mathrm{NF}-\kappa \mathrm{B}$ as the top pathway $(p=0.024)$ (Fig. 1A). Protein functions represented by the top differentially expressed genes (Supplementary Fig. S1C) included apoptosis, angiogenesis, proliferation, ubiquitylation, and transcription (Supplementary Table S4).

We correlated the fold change of gene expression in our RNA-seq data with that of a previously published microarray study comparing $\mathrm{CD} 34^{+}$cells from CP-CML patients who either responded or did not respond to imatinib [27]. Integration of genome-wide expression analyses with microarray data from this study identified 37 genes commonly dysregulated in TKI-resistant CML cell lines and patient samples (Fig. 1B and Supplementary Table S5). Of the 30 genes that are upregulated in TKI resistance, 21 are predicted to be $\mathrm{NF}-\kappa \mathrm{B}$ transcriptional targets based on data available from the University of California Santa Cruz Genome Browser (lymphoblastoid cell lines treated with TNF $\alpha$, data deposited by Michael Snyder's lab at Stanford University) (Fig. 1B) [33, 34]. Therefore, NF-кB may be driving the gene expression signature of TKI resistance. 


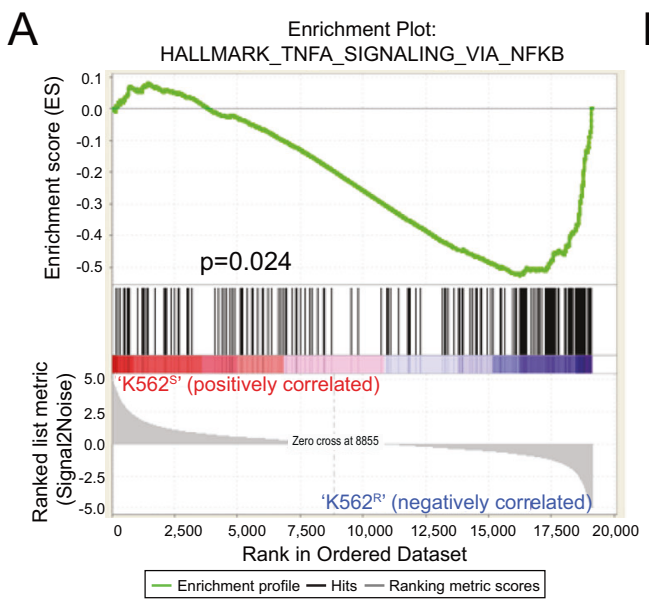

Fig. 1 Imatinib resistance associates with an NF-кB expression signature. A RNA from $\mathrm{K} 562^{\mathrm{S}}$ and $\mathrm{K} 562^{\mathrm{R}}$ cells were analyzed by RNA-seq to assess for differences in gene expression ( $n=3$ samples/ group). GSEA [77, 78] implicated the TNF $\alpha$ signaling pathway via NF- $\mathrm{KB}$ (FWER: $p=0.024$ ). B The heat map shows genes that were

\section{Nuclear NF-KB transcriptional activity is increased in TKI-resistant CML cell lines and primary CML CD34 cells}

It is well documented that NF- $\mathrm{KB}$ contributes to drug resistance in many different cancers [35-38]. In CML, NF-kB is activated by proteins like COBL11 [39] and TPL2 [40], and NF-kB inhibition was shown to sensitize TKI-resistant CML cells to imatinib [41-44]. However, the functional role of NF$\kappa \mathrm{B}$ transcriptional activity and the mechanism of activation in TKI resistance has not been explored. Confirming our RNAseq data linking NF- $\kappa \mathrm{B}$ with TKI resistance, TKI-resistant $\mathrm{K} 562^{\mathrm{R}}$ cells demonstrated a $70 \%$ increase of NF- $\mathrm{KB}$-mediated luciferase reporter activity compared to controls (Fig. 2A). Accordingly, nucleocytoplasmic fractionation followed by immunoblot analyses revealed a $75 \%$ increase of pNF- $\mathrm{kB}$ in the nucleus of $\mathrm{K} 562^{\mathrm{R}}$ cells compared with controls (Fig. 2B, C). Similar results were seen in primary, TKI-resistant CML $\mathrm{CD} 34^{+}$cells. We observed a twofold increase of pNF-kB levels in the nucleus of cells from two of three TKI-resistant CML patients compared with newly diagnosed CP-CML patients and normal donors (Fig. 2D, E). These data implicate a role for enhanced NF- $\mathrm{KB}$ transcriptional activity in driving the gene expression signature of TKI resistance in CML cell lines and patients who fail imatinib therapy.

\section{PSMD1 and PSMD3 expression is upregulated during $\mathrm{CML}$ disease progression}

It is well established that the UPS influences NF- $\kappa B$ activation and transcriptional activity $[25,26]$. We previously performed a functional genomics study using a pooled shRNA library on $\mathrm{K} 562^{\mathrm{R}}$ versus $\mathrm{K} 562^{\mathrm{S}}$ cells. This approach

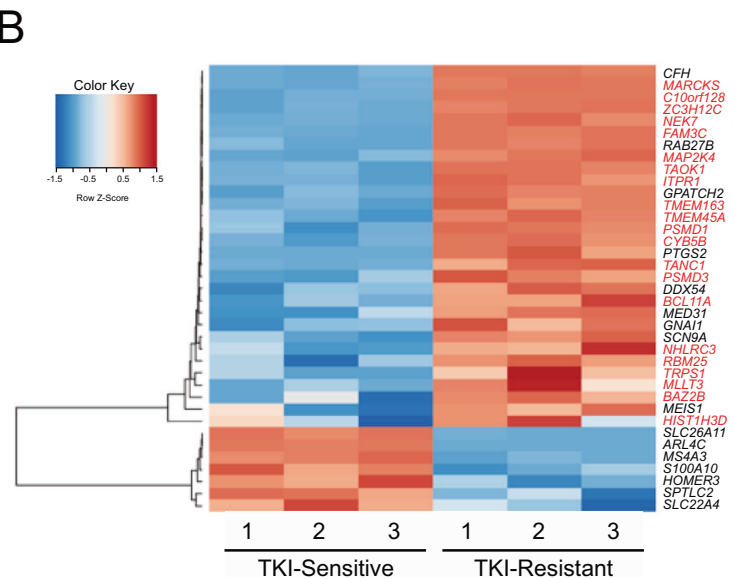

commonly dysregulated in both TKI-resistant cell lines and patient samples [27], identifying 30 upregulated genes and 7 downregulated genes. Of the 30 upregulated genes, 21 are predicted to harbor NF- $\kappa B$ binding sites in and around the promoter region (indicated in red).

identified five members of the UPS as genes critical to survival in TKI resistance, including NEDD8, PSMA1, PSMD1, PSMD3, and UBE1 [29]. Therefore, we searched for genes related to the UPS in our list of commonly dysregulated TKI resistance genes (Fig. 1 and Supplementary Table S5), identifying PSMD1 and PSMD3. PSMD1 and PSMD3 are non-ATPase subunits in the 19S regulatory complex of the UPS, which regulate proteasome substrate recognition and binding [30,31]. To date, the role of PSMD1 and PSMD3 in CML and NF- $\mathrm{KB}$ activation remains unknown.

RNA-seq data using specimens from CML patients with primary BCR-ABL1-independent resistance revealed that both PSMD1 and PSMD3 are upregulated in BP-CML patient samples compared with patients in the chronic or accelerated phases of the disease (Fig. 3A, B). These data are consistent with previously published microarray data on primary CML CD34 ${ }^{+}$cells by Radich et al. [28], indicating that PSMDI and PSMD3 are upregulated during CML disease progression. Immunoblot analysis on primary CD34 ${ }^{+}$ cells from normal cord blood versus that of a CML patient demonstrated that PSMD3 but not PSMD1 protein is upregulated in CML samples compared to normal controls (Fig. 3C). Thus, we hypothesized that PSMD3, and possibly PSMD1, may play a role in NF- $\mathrm{KB}$ activation during CML disease progression and imatinib resistance.

\section{Knockdown of PSMD1 or PSMD3 reduced survival and increased apoptosis in CML but not normal hematopoietic progenitor cells}

The proteasome inhibitor, bortezomib, was previously shown to induce apoptosis of primitive, TKI-resistant CML 
A

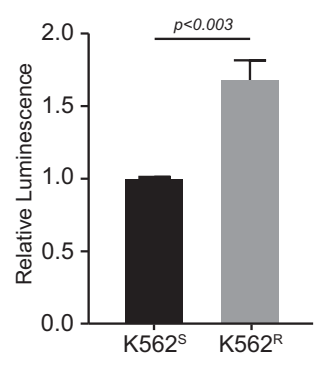

D
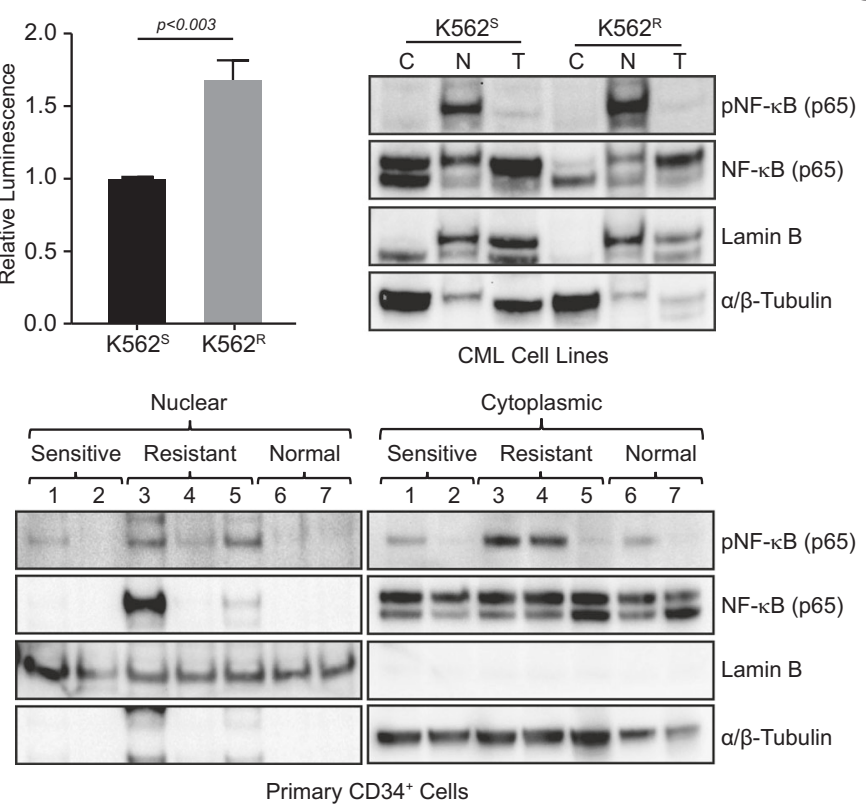

C

E
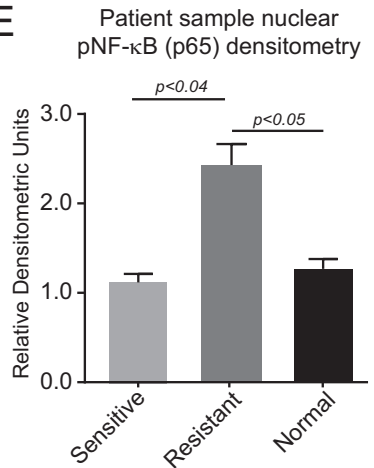

Fig. 2 Transcriptionally active NF- $\mathrm{BB}$ is increased in the nucleus of TKI-resistant CML cells. A Bar graphs represent relative luciferase reporter activity in $\mathrm{K} 562^{\mathrm{S}}$ versus $\mathrm{K} 562^{\mathrm{R}}$ cells $(n=5$ samples/ group) stably transduced with an NF- $\kappa B$ reporter versus a negative control. B Immunoblot shows NF- $\mathrm{B}$ and $\mathrm{pNF}-\mathrm{\kappa B}$ in the nucleus and cytoplasm of $\mathrm{K} 562^{\mathrm{S}}$ versus $\mathrm{K} 562^{\mathrm{R}}$ cells. C Bar graph represents densitometric calculations for separate replicates $(n=3)$ of the nucleocytoplasmic fractionation experiments presented in panel (B). Densitometric analysis was completed by normalizing against lamin B and tubulin in the nuclear and cytoplasmic fractions, respectively. D Immunoblot shows NF- $\mathrm{KB}$ and $\mathrm{pNF}-\kappa \mathrm{B}$ in the nucleus and cytoplasm of $\mathrm{CD}_{3} 4^{+}$cells from newly diagnosed, TKI-sensitive CP-CML patients $(n=2)$ versus TKI-resistant patients $(n=3)$ and normal donors $(n=2)$. Lamin B and tubulin were used to assess the quality of separation of the nuclear and cytoplasmic fractions, respectively. E Bar graph represents densitometric calculations for $\mathrm{pNF}-\kappa \mathrm{B}$ in panel (D). Error bars represent standard error of mean (SEM). C cytoplasmic fraction, $\mathrm{N}$ nuclear fraction, $\mathrm{T}$ total fraction.

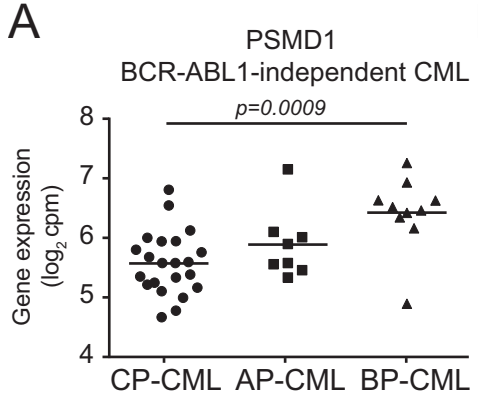

B

PSMD3 BCR-ABL1-independent CML

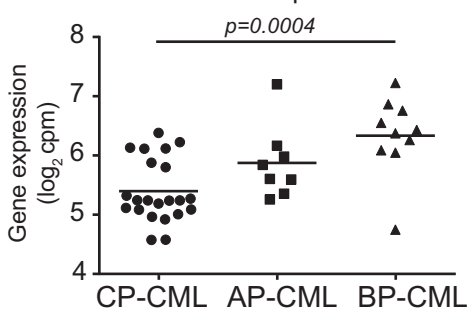

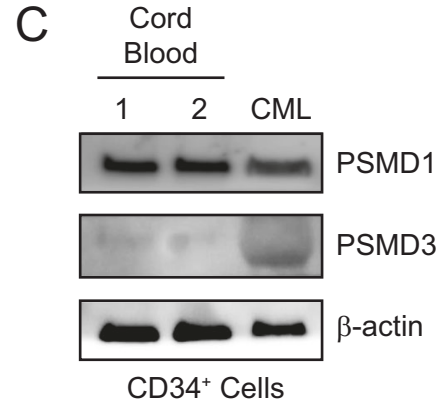

demonstrating BCR-ABL1-independent TKI resistance. C Immunoblot shows PSMD1 and PSMD3 protein levels in $\mathrm{CD}^{+} 4^{+}$cells from cord blood (lanes 1-2) versus a CP-CML patient (lane 3). $\beta$-actin was assessed as a loading control.
LSCs [45]. However, there was little efficacy and considerable toxicity observed in CML patients receiving bortezomib therapy [46, 47]. We reasoned that inhibition of PSMD1 or PSMD3 might represent a novel method for proteasome inhibition with less toxicity. To confirm the findings of our shRNA library screen [29], $\mathrm{K} 562^{\mathrm{S}}$ and $\mathrm{K} 562^{\mathrm{R}}$ cells were stably transduced with shRNA targeting PSMD1 (shPSMD1) or PSMD3 (shPSMD3). Using the same constructs that were hits in the shRNA library screen [29], we confirmed a 50-80\% knockdown at the mRNA and protein level upon doxycycline-induced knockdown (Supplementary Fig. S2A, B). Consistent with the library screen [29], shPSMD1 and shPSMD3 impaired the growth of $\mathrm{K} 562^{\mathrm{R}}$ cells by 9.5 -fold and 4.6-fold more than in $\mathrm{K}_{562} \mathrm{~S}$ cells, respectively, over the 9-day period (Fig. 4A, B). 
A

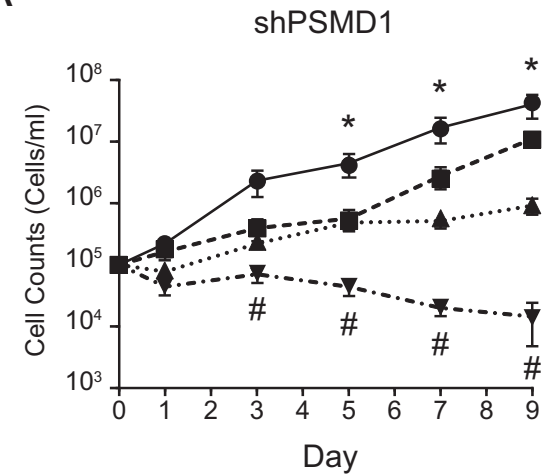

B

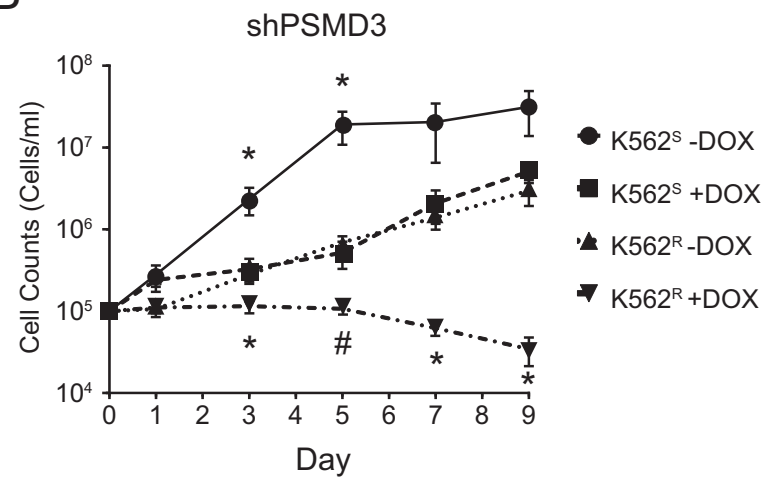

Fig. 4 Knockdown of the proteasome components, PSMD1 or PSMD3, resulted in a greater reduction of growth in TKI-resistant compared with TKI-sensitive K562 cells. Line graphs show cell growth in $\mathrm{K}_{562} \mathrm{~S}(n=3)$ and $\mathrm{K} 562^{\mathrm{R}}$ cells $(n=4)$ expressing shRNA

To further understand the role of PSMD1 and PSMD3 in CML and TKI response, we assessed the effects of shPSMD1 and shPSMD3 on colony forming ability and apoptosis in $\mathrm{K} 562^{\mathrm{S}}$ and $\mathrm{K} 562^{\mathrm{R}}$ cells compared with a non-targeting control vector (shNT). As expected, shNT had no effect on PSMD1 or PSMD3 mRNA or protein levels and did not alter colony forming ability in parental K562 cells (Supplementary Fig. S3A-C). PSMD1 and PSMD3 knockdown nearly ablated colony forming ability in both cell lines in the presence and absence of imatinib, which correlated with the induction of apoptosis (Fig. 5A, B). Knockdown of PSMD1 also reduced colony formation in $\mathrm{CD}_{3} 4^{+}$cells from a CP-CML patient by $50 \%$ (Fig. 5C). Similar experiments were performed in $\mathrm{CD} 34^{+}$cells harvested from normal cord blood. In contrast to our results in CML cells, knockdown of PSMD1 and PSMD3 had no effect on colony formation or apoptosis of cord blood CD $34^{+}$cells (Fig. 5D, E), suggesting a therapeutic window that could potentially be exploited.

Since PSMD3 and not PSMD1 was upregulated in CML CD $34^{+}$cells (Fig. 3C), we assessed whether PSMD3 knockdown altered K562 proliferation in vivo. K562 cells transduced with shPSMD3 or the shNT control were embedded in Matrigel and implanted into the rear flanks of nude mice. Ten days following injection, mice were placed on doxycycline chow to induce vector expression, and tumor size was evaluated over time. Knockdown of PSMD3 resulted in a significant reduction of subcutaneous tumor size by over threefold compared with shNT tumors (Fig. 6A-D). Altogether, our data implicate a role for the proteasome component, PSMD3, and possibly PSMD1, in disease progression and survival in CML. targeting PSMD1 (shPSMD1, (A)) or PSMD3 (shPSMD3, (B)) in the presence and absence of doxycycline $(100 \mathrm{ng} / \mathrm{ml})$ to induce the knockdown. Counts were recorded and graphed on a log scale. Error bars represent SEM. ${ }^{*} p<0.05 ;{ }^{*} p<0.01$.

\section{Knockdown of PSMD1 or PSMD3 reduced NF-KB protein expression and transcriptional activity in}

\section{CML cells that are both sensitive and resistant to imatinib}

To determine whether PSMD1 or PSMD3 regulates NF$\kappa \mathrm{B}$ activation in CML and TKI resistance, we used shRNAs to knockdown their expression in TKI-sensitive versus TKI-resistant CML cells. Knockdown of PSMD1 or PSMD3 protein resulted in global accumulation of ubiquitylated proteins in both cell lines, suggesting impaired protein deubiquitylation (Fig. 7A). This correlated with a reduction of both phospho-NF- $\mathrm{KB}$ and total NF- $\mathrm{\kappa B}$ protein expression (Fig. 7A). Densitometry revealed no difference in the relative reduction of NF- $\mathrm{KB}$ protein in TKI-resistant versus TKI-sensitive K562 cells in response to knockdown of either protein (Supplementary Fig. S4A, B). Consequently, shPSMD1 and shPSMD3 reduced NF-кB luciferase reporter activity by $90 \%$ in $\mathrm{K}_{562} \mathrm{~S}$ cells, but only $50 \%$ in $\mathrm{K} 562^{\mathrm{R}}$ cells, in the presence and absence of imatinib (Fig. 7B, C). These data indicate that PSMD1 and PSMD3 promote UPS-dependent NF- $\mathrm{BB}$ activation in $\mathrm{CML}$, and suggest that other factors are responsible for further activating NF- $\kappa \mathrm{B}$ during TKI resistance.

Next we assessed the sensitivity of $\mathrm{K} 562^{\mathrm{S}}$ versus $\mathrm{K} 562^{\mathrm{R}}$ cells to graded concentrations of the proteasome inhibitor, bortezomib, and found that TKI-resistant cells demonstrated cross-resistance to proteasome inhibition (Supplementary Fig. S5A). However, bortezomib reduced relative NF-кB luciferase reporter activity to a similar degree in both cell lines (Supplementary Fig. S5B). Altogether, these data suggest a potential role for alternative signaling pathways in activating NF- $\mathrm{KB}$ during TKI resistance. 


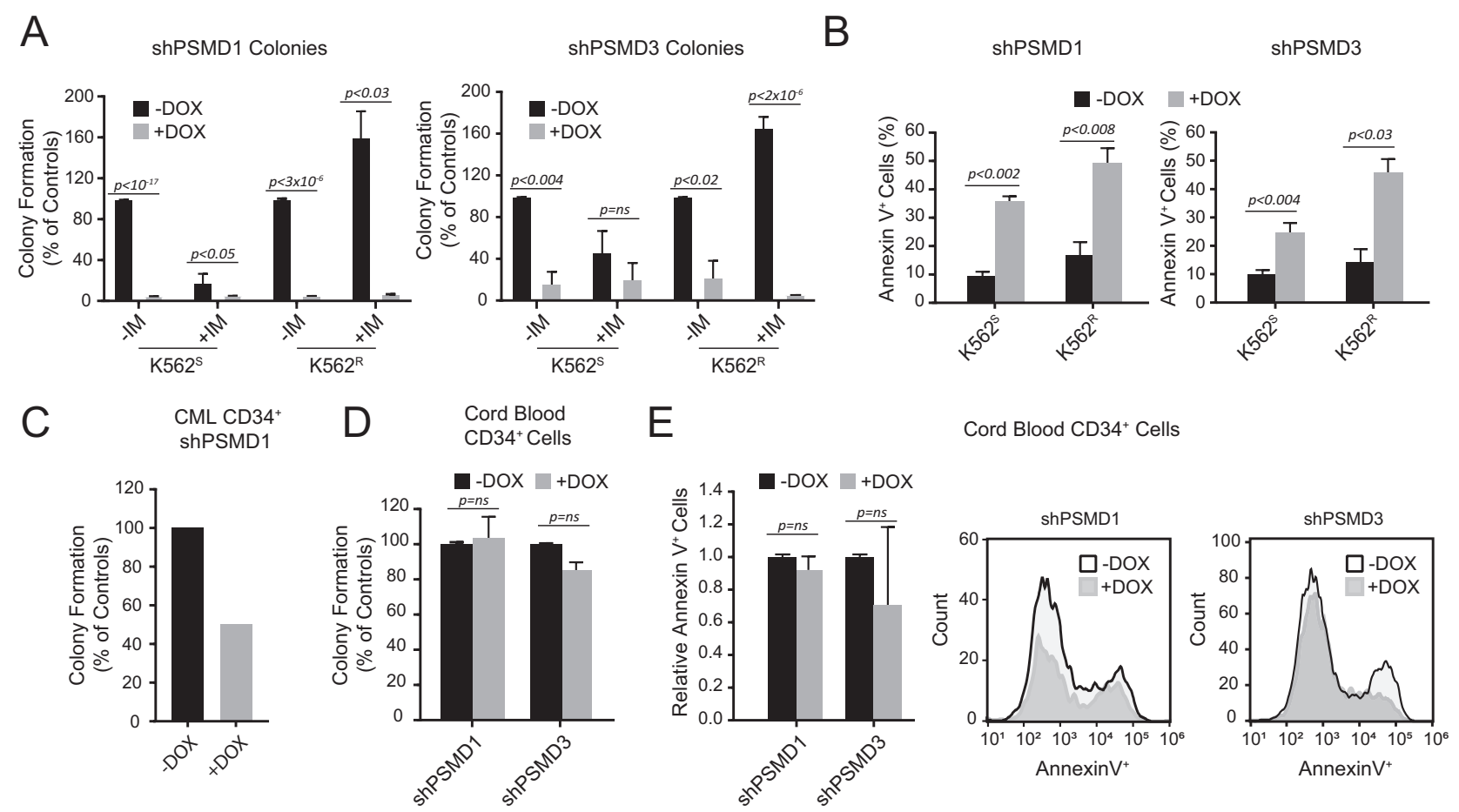

Fig. 5 shRNA-mediated knockdown of PSMD1 or PSMD3 impairs survival and induces apoptosis in CML but not normal progenitor cells. Bar graphs represent the effects of shPSMD1 or shPSMD3 on colony forming ability (A) or AnnexinV positivity (B) in $\mathrm{K} 562^{\mathrm{S}}$ and $\mathrm{K} 562^{\mathrm{R}}$ cells with and without imatinib $(1 \mu \mathrm{M})$ or doxycycline $(100 \mathrm{ng} / \mathrm{ml})$ as indicated (at least three samples were analyzed for all groups tested). C Bar graph represents the effects of shPSMD1 on colony formation of $\mathrm{CD} 34^{+}$cells from a CP-CML patient cultured \pm

\section{STAT3 and not TNFa is responsible for activating NF-KB in TKI-resistant CML}

Knockdown of PSMD1 or PSMD3 reduced NF- $\mathrm{KB}$ reporter activity by $\sim 90 \%$ and $\sim 50 \%$ in $\mathrm{K} 562^{\mathrm{S}}$ and $\mathrm{K} 562^{\mathrm{R}}$ cells, respectively (Fig. 7B, C). Therefore, we hypothesized that other factors are responsible for further activation of NF- $\mathrm{KB}$ during TKI resistance. Constitutive NF- $\mathrm{KB}$ activation upregulates the expression of major inflammatory mediators, including TNF $\alpha$, interleukin-6 (IL-6), IL-1, and IL-8, to promote cell proliferation and inhibit apoptosis [48, 49]. TNF $\alpha$ and IL-6 have been shown to support stem and progenitor cell survival and proliferation in CML [50-53]. Additionally, several groups have reported a role for cytokines in the CML bone marrow microenvironment [53-57], and blockade of extrinsic survival signals was shown to restore sensitivity of CML cells to TKIs [58, 59]. Since our RNA-seq data implicated TNF $\alpha$ signaling via NF- $\kappa B$, we hypothesized that autocrine TNF $\alpha$ production was responsible for further NF- $\kappa B$ activation in TKI resistance. TNF $\alpha$ was previously reported to activate NF-kB in AML [60]. We first measured TNFA and IL6 mRNA by reverse transcription quantitative polymerase chain reaction (RT-qPCR) doxycycline $(100 \mathrm{ng} / \mathrm{ml})$ to induce the knockdown. SARS-CoV-2 2019 (COVID-19) prevented completion of these experiments in additional patient samples. D Bar graph represents colony forming ability ( $n=5$ samples/group) of cord blood CD $34^{+}$cells expressing shPSMD1 or shPSMD3 in the presence and absence of doxycycline. E Bar graph and histograms demonstrate AnnexinV positivity in cord blood $\mathrm{CD}_{3} 4^{+}$cells expressing shPSMD1 or shPSMD3 in the presence and absence of doxycycline $(n=2)$.

in both $\mathrm{K} 562^{\mathrm{S}}$ and $\mathrm{K} 562^{\mathrm{R}}$ cells either untreated or treated with imatinib. Imatinib treatment markedly increased TNFA mRNA expression in both $\mathrm{K} 562^{\mathrm{S}}$ and $\mathrm{K} 562^{\mathrm{R}}$ cells, with no observable differences between the two groups (Fig. 8A). In contrast, IL6 mRNA expression was completely abolished by imatinib treatment, again with no observable differences between the cell lines (Fig. 8A). Next we performed Enzyme-linked immunosorbent assays (ELISAs) to assess for autonomous TNF $\alpha$ or IL-6 secretion at the protein level. In contrast with our RNA-seq data, TNF $\alpha$ production was low in both $\mathrm{K} 562^{\mathrm{S}}$ and $\mathrm{K} 562^{\mathrm{R}}$ cells in the presence or absence of imatinib, and there was no difference between the two groups (Fig. 8B). IL-6, on the other hand, was significantly reduced by imatinib treatment in $\mathrm{K}^{2} 62^{\mathrm{S}}$ cells, and markedly increased in $\mathrm{K} 562^{\mathrm{R}}$ cells under all treatment conditions (Fig. 8C).

Our previous work demonstrated that CML stem and progenitor cells that are TKI-resistant, but lack BCRABL1 kinase domain mutations, are dependent on STAT3 and susceptible to STAT3 inhibition $[19,20]$. The NF- $\mathrm{KB}$ and STAT3 signaling pathways have been shown to functionally interact with each other in many different scenarios [61-66]. To assess whether STAT3 plays a role 
A

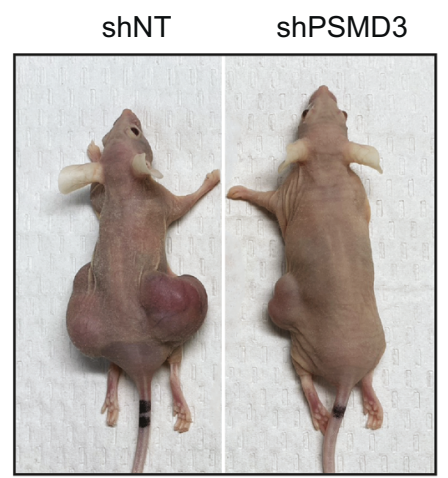

C

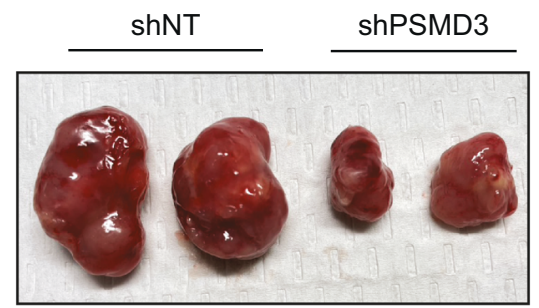

B
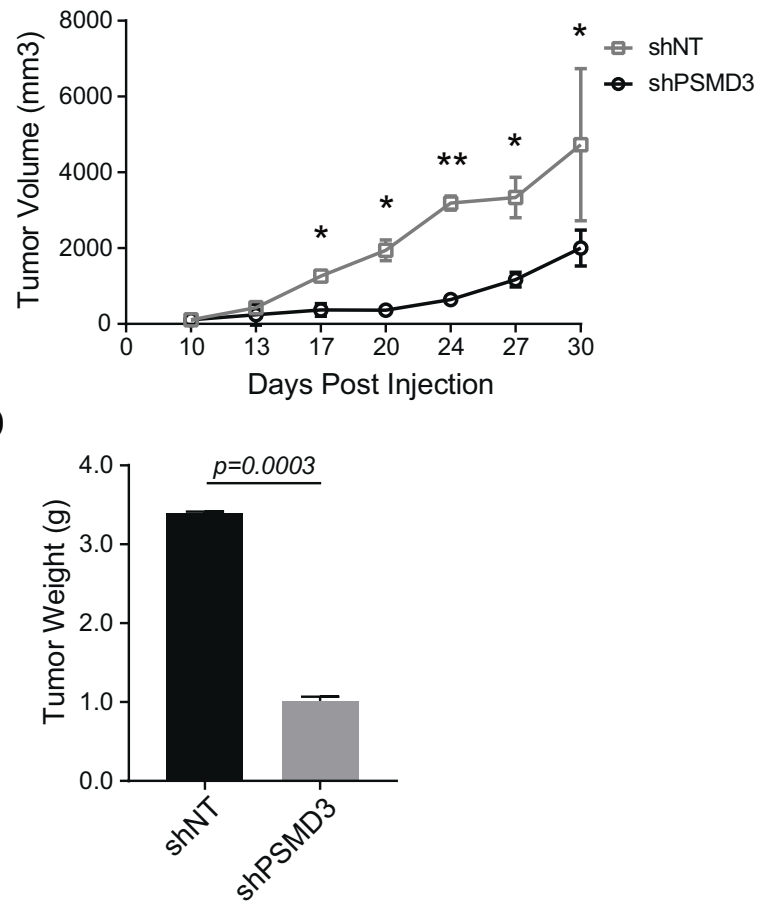

graph shows the rate of tumor growth of K562 cells transduced with shNT versus shPSMD3 implanted into the rear flanks of nude mice ( $n=2$ /group). Image and bar graph shows tumor sizes $(\mathbf{C})$ and weights (D). Error bars represent the mean $(* p<0.05 ; * *<0.01)$.

demonstrated that combined inhibition of STAT3 and BCRABL1 induced synthetic lethality in therapy-resistant CML cell lines and patient samples [19, 20]. However, SH2 domain-containing proteins like STAT3 are challenging molecular targets, because inhibition results in off-target effects [67]. To identify drivers of TKI resistance, we performed RNA-seq on TKI-resistant versus parental K562 cells. Surprisingly, GSEA did not reveal a STAT3 transcriptional signature, but was rather reminiscent of TNF $\alpha$ signaling via NF- $\mathrm{kB}$ (Fig. 1). In the present study, we elucidated the mechanism by which NF- $\mathrm{\kappa B}$ is activated in CML and TKI resistance, implicating two important and novel findings: (1) the non-ATPase proteasome subunits, PSMD1 and PSMD3, are upregulated during CML disease progression (Fig. 3) and promote NF- $\kappa \mathrm{B}$ protein expression in CML (Fig. 7), and (2) STAT3 further activates NF-אB in scenarios of TKI resistance (Fig. 8). This is a relevant finding, because it implicates noncanonical functions for STAT3 during drug resistance of CML.

Interestingly, our data suggest that knockdown of PSMD1 or PSMD3 has differential effects on cell growth versus survival signals in CML. In cell growth assays, knockdown of either protein resulted in a greater reduction of growth in TKI-resistant compared with TKI-sensitive 

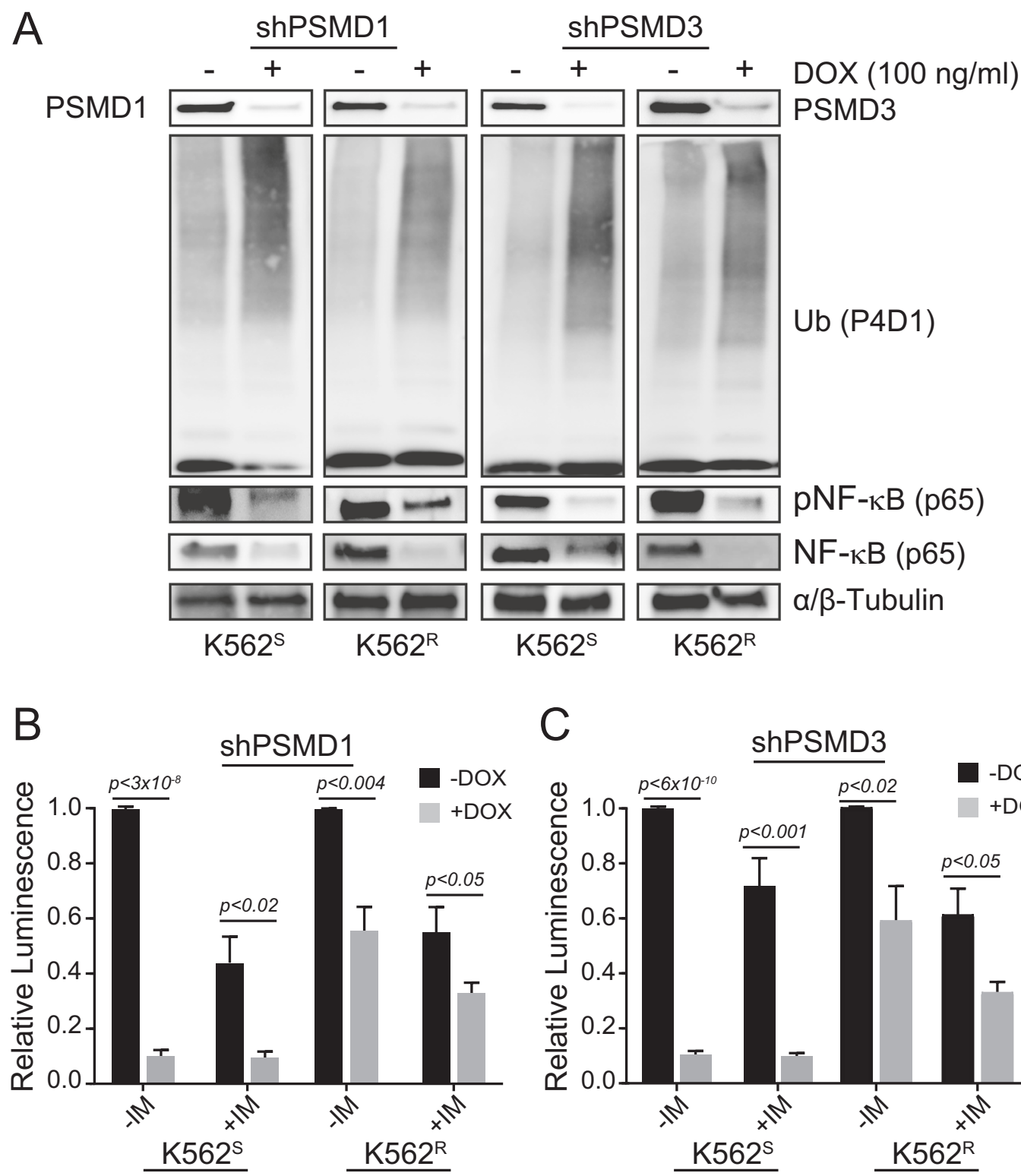

Fig. 7 PSMD1 and PSMD3 regulate NF- $\kappa B$ expression and transcriptional activity in TKI-sensitive and TKI-resistant CML cells. A Immunoblot shows the effects of shPSMD1 (left) and shPSMD3 (right) on levels of ubiquitylated proteins, total NF- $\mathrm{KB}$ p65, and phospho-NF-kB p65 in both $\mathrm{K} 562^{\mathrm{S}}$ and $\mathrm{K} 562^{\mathrm{R}}$ cells upon knockdown

cells (Fig. 4). This is consistent with our previous findings in a shRNA library screen [29]. In contrast, PSMD1 or PSMD3 knockdown in either cell line had similar effects on reducing survival in colony formation assays (Fig. 5). This suggests that these proteins differentially control cell growth but not survival signals in TKI resistance. While PSMD1 and PSMD3 were identified as markers of TKI resistance, they did not play a greater role in activating NF$\kappa B$ in TKI-resistant versus sensitive cells. Therefore, these proteins may alter the expression of additional peptide targets that have yet to be discovered, a subject for future

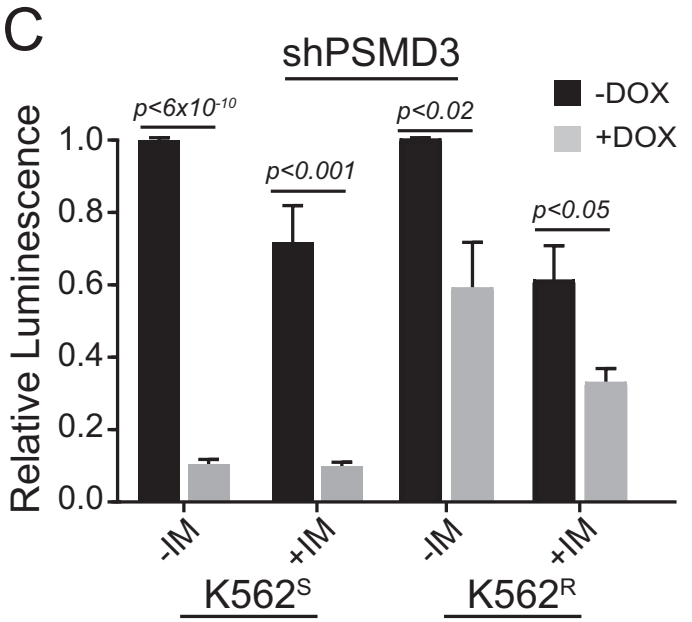

of PSMD1 and PSMD3 protein ( $n=3$ samples/group). Bar graphs

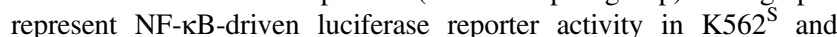
K562 ${ }^{\mathrm{R}}$ cells lentivirally transduced with shPSMD1 $(\mathbf{B})(n=4)$ or shPSMD3 (C) $(n=3) \pm$ doxycycline $(100 \mathrm{ng} / \mathrm{ml}, 72 \mathrm{~h})$ to induce the knockdown. Error bars represent SEM.

investigation. Surprisingly, TKI-resistant cells demonstrated resistance to the proteasome inhibitor, bortezomib, despite having increased sensitivity to PSMD1 or PSMD3 knockdown in cell growth assays. However, we speculate that this may be due to the presence of STAT3. We have already reported activation of STAT3 at tyrosine $705\left(\right.$ pSTAT3 $\left.^{\mathrm{Y} 705}\right)$ in TKI resistance, and that dual targeting of STAT3 and BCR-ABL1 induced synthetic lethality in TKI-resistant CML $[19,20]$. Importantly, the JAK1/STAT3 pathway was previously shown to alter proteasome inhibitor sensitivity in multiple myeloma [68], and therefore could possibly induce 
A

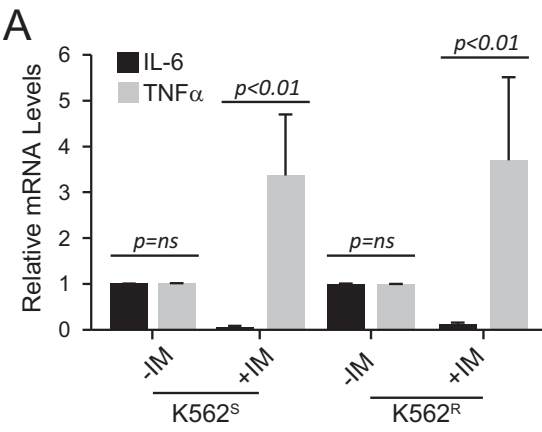

D

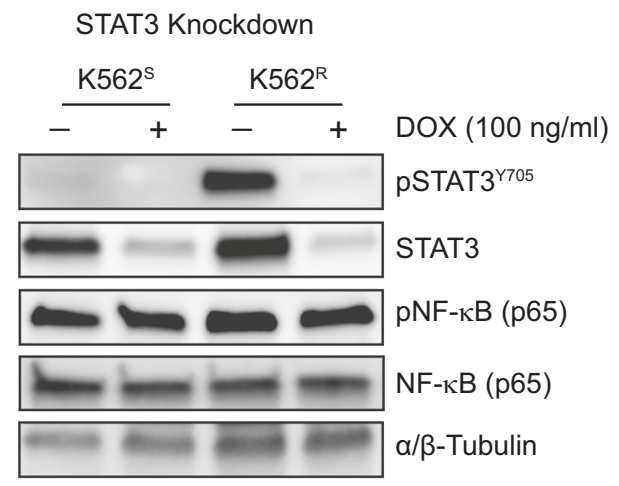

Fig. 8 A role for IL-6 and STAT3 in activation of NF-кB transcriptional activity in TKI resistance. A Bar graph shows relative IL6 and TNFa mRNA levels in TKI-sensitive K562 ${ }^{\mathrm{S}}$ cells versus TKIresistant $\mathrm{K} 562^{\mathrm{R}}$ cells in the presence and absence of imatinib $(1 \mu \mathrm{M}$, $24 \mathrm{~h})$. Bar graphs represent the concentration of TNF $\alpha(\mathbf{B})$ or IL-6 (C) produced by $\mathrm{K} 562^{\mathrm{S}}$ versus $\mathrm{K} 562^{\mathrm{R}}$ cells in the presence and absence of imatinib $(1 \mu \mathrm{M}, 24 \mathrm{~h})$. D Immunoblot shows total STAT3, phospho-

bortezomib resistance in the case of TKI-resistant CML. STAT3-mediated NF- $\mathrm{KB}$ activation likely also explains the reduced effects of PSMD1 or PSMD3 knockdown on NF$\kappa \mathrm{B}$ transcriptional activity that we observed in TKI-resistant versus TKI-sensitive cells, as seen in Fig. 7B, C.

The UPS is responsible for targeted protein degradation using three catalytic specificities: chymotrypsin-like, trypsin-like, and post-glutamyl hydrolytic [45]. It has long been established that the UPS plays an important role in NF- $\mathrm{KB}$ activation [69], and five members of the UPS were hits in a previously published shRNA library screen for TKI resistance [29]. Our data suggest that PSMD1 and PSMD3 are upregulated upon CML disease progression and regulate $\mathrm{NF}-\kappa \mathrm{B}$ protein expression, transcriptional activity, and cell growth. We speculate that the difference in sensitivity between CML and normal progenitors to knockdown of PSMD1 or PSMD3 may be due to differences in posttranslational modifications (PTMs), which could alter peptide targets in malignant versus normal tissues. It was previously reported that PSMD1 functions in the proteasome by acting as an ubiquitin receptor, binding of peptide substrates, and gate opening, which could be subject to
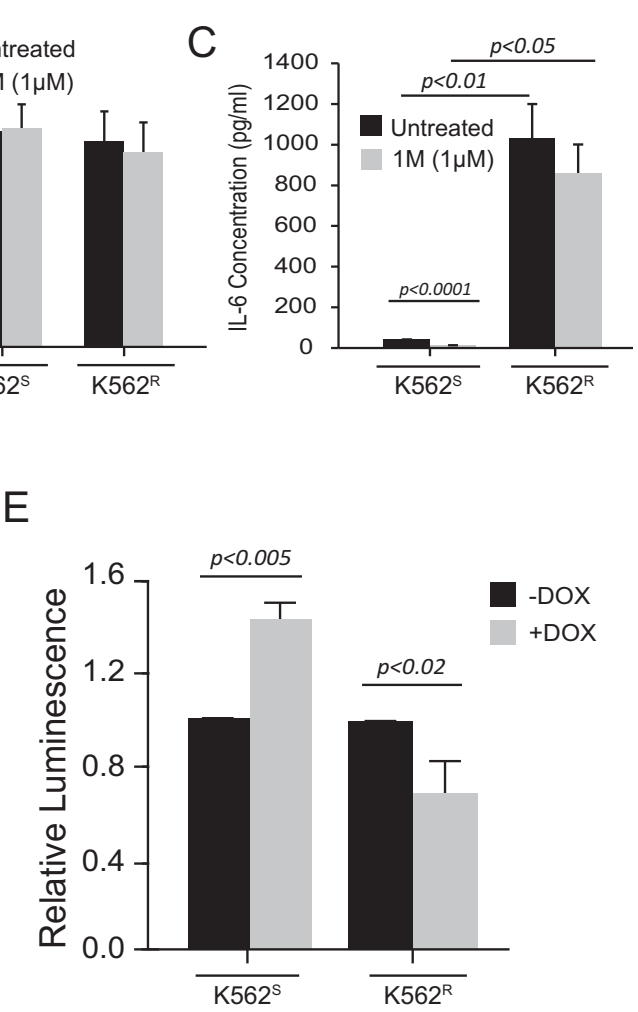

$\mathrm{STAT}^{\mathrm{Y} 705}{ }^{\text {, total NF- }} \mathrm{\kappa B}$, and phospho-NF- $\mathrm{KB}$ in $\mathrm{K} 562^{\mathrm{S}}$ and $\mathrm{K} 562^{\mathrm{R}}$ cells upon induction of shRNA targeting STAT3 (shSTAT3) with doxycycline $(100 \mathrm{ng} / \mathrm{ml}, 72 \mathrm{~h})$. E Bar graph represents NF- $\mathrm{KB}$ luciferase reporter activity in $\mathrm{K} 562^{\mathrm{S}}$ versus $\mathrm{K} 562^{\mathrm{R}}$ cells upon induction of shSTAT3 with doxycycline $(100 \mathrm{ng} / \mathrm{ml}, 72 \mathrm{~h})$. Error bars represent SEM.

several different PTMs (e.g., SUMOylation, $\mathrm{N}$-acetylation, succinylation, and S-glutathionylation) [70]. As you can see in Fig. 3C, PSMD3 protein in CML CD34 ${ }^{+}$cells migrated farther on the gel than PSMD3 in cord blood, suggesting aberrant PTMs. In breast cancer, PSMD1 was shown to induce p53 protein degradation [30], whereas PSMD3 protected HER2 from degradation in HER2-positive breast cancers [31]. We propose that PSMD1 and PSMD3 protect NF- $\mathrm{KB}$ protein from degradation. In addition to PTMs that alter peptide substrates, another potential difference between CML and normal cells could be differential expression of proteins targeted for degradation. Saccani et al. [71] previously reported that the proteasome represses NF- $\mathrm{KB}$ transcriptional activity by direct polyubiquitination and degradation of p65 in the nucleus. These results indicate that proteasome-dependent degradation of NF- $\mathrm{KB}$ not only regulates its protein stability and abundance, but also actively promotes transcriptional termination. Future studies will explore PTMs and peptide targets of PSMD1 and PSMD3 in myeloid malignancies.

Similar to our findings, Fisher et al. reported increased phosphorylation and activation of NF-kB in myeloproliferative 
disorders, which was dependent on TNF $\alpha$ stimulation in hematopoietic stem and progenitor cells. Their results demonstrated that, in cells of patients with myelofibrosis and secondary AML, the NF- $\kappa \mathrm{B}$ pathway was constitutively active and hypersensitive to cytokine stimulation compared with controls [72]. Tsvetkov et al. [73] reported that reduced mRNA expression of at least one 19S proteasome component, including PSMD1, PSMD5, PSMD6, or PSMD10, correlated with loss of $\mathrm{TNF} \alpha / \mathrm{NF}-\kappa \mathrm{B}$ signaling in myeloma cells that are resistant to the proteasome inhibitors, MG132, bortezomib, and carfilzomib. This agrees with our findings, in that shRNAmediated knockdown of PSMD1 or PSMD3 in CML cells reduced $\mathrm{NF}-\kappa \mathrm{B}$ protein expression and transcriptional activity (Fig. 7), suggesting that PSMD1 and PSMD3 regulate NF- $\mathrm{B}$ protein expression, rather than targeting the canonical signaling pathway. In contrast with our findings, low expression of proteasome components correlated with higher relapse rates and a lower overall survival in myeloma patients [73]. Since high levels of PSMD3 mRNA correlated with a worse overall survival in AML [32], our data suggest tissue-specific roles for these proteins during malignant transformation of different tissue types. Additional studies will be required to determine if similar pathways are involved in the progression of other types of cancers. Altogether, our data suggest a role for PSMD1, PSMD3, and STAT3 in regulating NF- $\kappa$ B expression and activity in CML and TKI resistance, and implicate them as potential targets for the treatment of hematologic malignancies and possibly other forms of cancer.

\section{Methods}

\section{Cell lines and patient samples}

Details on the cell lines used in this study are available in Supplementary Methods. Primary mononuclear cells (MNCs) from discarded cord blood from the University Medical Center of El Paso (El Paso, TX, USA) were Ficollseparated (Life Technologies, Carlsbad, CA, USA) and used for selection of the $\mathrm{CD} 34^{+}$population (StemCell Technologies Inc., Vancouver, Canada). $\mathrm{CD}^{+}{ }^{+}$cells represent the disease-causing stem and progenitor population in CML. A purity of $>90 \%$ was confirmed by flow cytometry using FITC anti-human CD34 (BioLegend Inc., San Diego, CA, USA). CD34 ${ }^{+}$cells from peripheral blood of CML patients or normal donors that were used for nucleocytoplasmic fractionation (see below) were obtained from the Centre for Haematology at Imperial College London (London, UK). Cells $\left(2 \times 10^{6}\right)$ were lysed directly for use in molecular biology assays. This study was approved by the Texas Tech University Health Sciences Center El Paso Institutional Review Board (IRB) and by the Imperial College Research Ethics Committee. All patients gave informed consent and all experiments were performed in accordance with the Declaration of Helsinki.

\section{RNA sequencing (RNA-seq)}

Detailed information on RNA-seq experiments is provided in Supplementary Methods. RNA-seq data generated in cell lines (GSE149623) were correlated with HG-U133 microarray data on $\mathrm{CML} \mathrm{CD} 34^{+}$cells from TKI-resistant patients in a published data set (GSE14671) [27]. Genes were selected as having $p<0.01$ and a fold change $>1.5$ in both studies. Heat maps were produced using the "gplots" package on R3.3.2 [74]. Gene-level expression data for PSMD1 and PSMD3 were also obtained from primary CML patient MNCs isolated from either peripheral blood or bone marrow and subjected to paired-end $2 \times 150 \mathrm{bp}$ RNA-seq using the Illumina platform (part of a larger, separate study: Eide et al. manuscript in preparation). All patients exhibited BCR-ABL1-independent TKI resistance, and were separated by disease phase: CP-CML $(n=22)$, accelerated phase CML (AP-CML, $n=8)$, and BP-CML $(n=10)$. This study was approved by the Oregon Health \& Science University IRB.

\section{Reverse transcription quantitative polymerase chain reaction (RT-qPCR)}

Total RNA was extracted using the PureLink RNA Mini Kit by Invitrogen (Thermo Fisher Scientific, Waltham, MA, USA) and quantified using a NanoDrop ${ }^{\mathrm{TM}} 2000$ (Thermo Fisher Scientific). RT-qPCR was performed with the Luna Universal One-Step qPCR Kit (New England Biolabs, Ipswich, MA, USA) on a StepOnePlus Real-Time PCR System (Applied Biosystems, Foster City, CA, USA). GUSB mRNA levels were measured as a control; primer sequences are listed in Supplementary Table S1. Assays were performed in triplicate and relative expression was analyzed using the comparative cycle threshold method $\left(2^{-\Delta \Delta \mathrm{Ct}}\right)$.

\section{Immunoblot}

$\mathrm{K} 562^{\mathrm{S}}$ and $\mathrm{K} 562^{\mathrm{R}}$ cells and derivative lines were cultured as indicated, and resulting cells $\left(10^{6}\right)$ were lysed $\left(4^{\circ} \mathrm{C}\right.$; $30 \mathrm{~min}$ ) in 1X RIPA buffer (Cell Signaling Technology Inc., Danvers, MA, USA) containing protease inhibitors (PMSF, Thermo Fisher Scientific) and phosphatase inhibitors (PhosSTOP, Roche, Basel, Switzerland). For primary samples, $3 \times 10^{4} \mathrm{CD} 34^{+}$cells were lysed directly in sample buffer. All samples were denatured $\left(100{ }^{\circ} \mathrm{C}\right.$; 10 min) followed by SDS-PAGE and transfer to PVDF membranes. $\alpha / \beta$-tubulin or $\beta$-actin was assessed as a loading control; antibodies are listed in Supplementary Table S2. 


\section{Nucleocytoplasmic fractionation}

For detection of total- and phospho-NF- $\mathrm{kB}$ p65 in CML cell lines and primary $\mathrm{CD} 34^{+}$cells, nuclear and cytoplasmic extracts were separated from $2 \times 10^{6}$ cells prior to immunoblot using the Nuclear/Cytosol Fractionation Kit (BioVision, Inc., Milpitas, CA, USA). Lysis of membranes with preservation of nuclei was confirmed by light microscopy. Antibodies against $\alpha / \beta$-tubulin and Lamin B1 were used to assess purity of the cytoplasmic and nuclear fractions, respectively (Supplementary Table S2). Densitometry was conducted using ImageJ (NIH, Bethesda, MD, USA).

\section{Constructs and lentivirus production}

Lentiviral shRNA constructs targeting PSMDI (RefSeq: NM_002807.2), PSMD3 (RefSeq: NM_002809.2), STAT3 (RefSeq: NM_139276.2), and a non-targeting control vector (shNT) were purchased from Cellecta (Mountain View, CA, USA). The vector sequences were identified from our previously published shRNA library screen [29]. The pGreenFire NF-kB luciferase reporter system was purchased from System Biosciences, LLC (Palo Alto, CA, USA) (Supplementary Table S3). Detailed information on lentivirus production is provided in Supplementary Methods.

\section{Luciferase reporter assays}

To detect endogenous NF- $\mathrm{kB}$ transcriptional activity, CML cell lines were lentivirally transduced with the pGreenFire1NF-кB Lentivector reporter system (Supplementary Table S3) using the protocol outlined in Supplementary Methods. Stably transduced cells were selected by 10 days of culture in the presence of Geneticin ${ }^{\mathrm{TM}}$ (Life Technologies). CML cells containing the pGreenFire1-NF- $\kappa \mathrm{B}$ reporter system were seeded at 5000 cells per well on a sterile black flatbottom 96-well plate (Greiner Bio-One, Kremsmünster, Austria). Luciferase reporter activity was recorded $72 \mathrm{~h}$ following treatment using the ONE-Glo Luciferase Assay System (Promega Corporation, Madison, WI, USA) on a CLARIOstar ${ }^{\bullet}$ Plus (BMG Labtech, Ortenberg, Germany).

\section{Apoptosis assays}

Following doxycycline $(100 \mathrm{ng} / \mathrm{ml}, 72 \mathrm{~h})$ treatment with and without the indicated inhibitors, apoptosis was measured by staining cells with APC-conjugated AnnexinV (BioLegend Inc.) in combination with 7-aminoactinomycin D (eBioscience at Thermo Fisher Scientific). Resulting cells were analyzed using a BD FACSCanto II (BD Biosciences, San Jose, CA, USA), and the data were processed through FlowJo (Ashland, OR, USA).

\section{Time course assay}

$\mathrm{K} 562^{\mathrm{S}}$ and $\mathrm{K} 562^{\mathrm{R}}$ cells expressing shPSMD1 or shPSMD3 were plated at a density of $1.0 \times 10^{5}$ cells $/ \mathrm{ml} \pm$ doxycycline $(100 \mathrm{ng} / \mathrm{ml})$ to induce the knockdown. Cells were counted every other day for 9 days by trypan blue exclusion, with media changes and expansion as needed to maintain exponential growth.

\section{Colony formation assays}

Methylcellulose colony formation assays were performed by plating of CML cell lines or primary $\mathrm{CD} 34^{+}$cells $\left(10^{3}\right.$ cells/dish) in $0.9 \%$ MethoCult (StemCell Technologies) as previously described [19]. Briefly, CML cell lines were plated in cytokine-free conditions \pm imatinib $(1.0 \mu \mathrm{M})$ and/ or doxycycline $(100 \mathrm{ng} / \mathrm{ml})$ to induce shRNA-mediated knockdown. For $\mathrm{GFP}^{+} \mathrm{CD} 34^{+} \mathrm{CML}$ or cord blood cells expressing shPSMD1 or shPSMD3, cells were plated in the presence of $1 \mathrm{X}$ StemSpan ${ }^{\mathrm{TM}} \mathrm{CD} 34^{+}$Expansion Supplement (StemCell Technologies) \pm doxycycline $(100 \mathrm{ng} / \mathrm{ml})$. Colonies were scored after 7-14 days of culture in a humidified chamber at $37{ }^{\circ} \mathrm{C}$ with $5 \% \mathrm{CO}_{2}$.

\section{Enzyme-linked immunosorbent assay (ELISA)}

To detect autonomous production of tumor necrosis factor alpha (TNF $\alpha$ ) or IL-6, K562 ${ }^{\mathrm{S}}$ and $\mathrm{K} 562^{\mathrm{R}}$ cells were cultured at $1 \times 10^{6}$ cells/ml for $24 \mathrm{~h}$, and resulting supernatants were harvested and stored at $-80^{\circ} \mathrm{C}$. TNF $\alpha$ was detected using the Human TNF-alpha Quantikine ELISA Kit (R\&D Systems, Inc., Minneapolis, MN, USA, \#DTA00D), and IL-6 was detected using the Human IL-6 Quantikine ELISA Kit (R\&D Systems, Inc., \#D6050) according to the manufacturer's instructions. Signals were quantified on a CLARIOstar ${ }^{\circledast}$ Plus (BMG Labtech) plate reader.

\section{Subcutaneous injections}

Wild-type K562 cells were lentivirally transduced with shNT or shPSMD3 (Cellecta) and selected in puromycin $(2 \mu \mathrm{g} / \mathrm{ml}, 72 \mathrm{~h})$. To generate subcutaneous tumors, $3 \times 10^{6}$ cells were mixed with $100 \mu$ of Matrigel basement membrane matrix (Corning Inc., Corning, NY, USA \#356234), and injected subcutaneously into the rear left and right flanks of 6-8-week-old nude mice (Jackson Laboratories \#002019). Tumor size was measured every 3-4 days, and volume was calculated as previously described [75, 76]. Ten days after implantation, all mice were placed on $625 \mathrm{mg} / \mathrm{kg}$ doxycycline hyclate (Envigo Teklad, Indianapolis, IN, USA \#TD.01306), and tumor size was measured over time. After 21 days, mice were euthanized and tumors removed for gross examination. Mice were not randomized, 
and the investigator was not blinded during image analysis. All experiments were performed with approval by the Institutional Animal Care and Use Committee at Texas Tech University Health Sciences Center El Paso.

\section{Statistical analyses}

For all assays, three independent experiments were performed unless otherwise noted. A two-tailed Student's $t$ test was used for cell line, mouse, and cord blood data demonstrating equivocal variance. Patient sample RNA-seq data were analyzed by one-way analysis of variance in GraphPad Prism version 7.05. All error bars represent standard error of the mean, and a $p$ value of $<0.05$ was considered statistically significant. For gene expression analyses, a $p$ value of $<0.01$ was considered statistically significant. No statistical method was used for predetermination of sample size.

Acknowledgements The authors would like to thank the Imperial BRC Genomics Facility, Imperial College London for providing resources and support that have contributed to the results reported within this paper. The Imperial BRC Genomics Facility is supported by the National Institute for Health Research (NIHR) to the Imperial Biomedical Research Centre. Research reported in this publication was supported in part by the National Cancer Institute of the National Institutes of Health under award numbers K22CA216008-04 (AME) and R01CA065823-21 (BJD). The content is solely the responsibility of the authors and does not necessarily represent the official views of the National Institutes of Health. CBV is grateful for scholarship obtained through support from Consejo Nacional de Ciencia y Tecnología (CONACyT). We also wish to thank Michael Deininger, MD, $\mathrm{PhD}$, from the University of Utah Huntsman Cancer Institute, for providing the cell lines used in this study. We thank Jessica M. Hernando, MT, ASCP (CM) and her team at the University Medical Center of El Paso (El Paso, TX, USA) for graciously donating the discarded cord blood used in this study. The authors are thankful to Shrikanth Gadad, PhD and Rajkumar Lakshmanaswamy, PhD for critical review of the paper.

Author contributions AME, JSK, AEBA, MAG, and AJR designed the study, fulfilled compliance requirements, collected and analyzed data, performed the analyses, made figures and tables, and wrote the paper; IMO, RE, CRF, JJL, and CBV made figures and tables and wrote the paper; CAE, LFJS, GN, AGR, DM, BJD, and JA provided samples and clinical information, performed experiments, provided technical insight, and critically reviewed the paper.

\section{Compliance with ethical standards}

Conflict of interest BJD's potential competing interests-SAB: Aileron Therapeutics, Therapy Architects (ALLCRON), Cepheid, Vivid Biosciences, Celgene, RUNX1 Research Program, EnLiven Therapeutics, Gilead Sciences (inactive), Monojul (inactive); SAB and stock: Aptose Biosciences, Blueprint Medicines, Iterion Therapeutics, Third Coast Therapeutics, GRAIL (SAB inactive); scientific founder: MolecularMD (inactive, acquired by ICON); board of directors and stock: Amgen; board of directors: Burroughs Wellcome Fund, CureOne; joint steering committee: Beat AML LLS; founder: VB Therapeutics; clinical trial funding: Novartis, Bristol-Myers Squibb, Pfizer;
Royalties from Patent 6958335 (Novartis exclusive license) and OHSU and Dana-Farber Cancer Institute (one Merck exclusive license). The remaining authors have no competing interests.

Publisher's note Springer Nature remains neutral with regard to jurisdictional claims in published maps and institutional affiliations.

Open Access This article is licensed under a Creative Commons Attribution 4.0 International License, which permits use, sharing, adaptation, distribution and reproduction in any medium or format, as long as you give appropriate credit to the original author(s) and the source, provide a link to the Creative Commons license, and indicate if changes were made. The images or other third party material in this article are included in the article's Creative Commons license, unless indicated otherwise in a credit line to the material. If material is not included in the article's Creative Commons license and your intended use is not permitted by statutory regulation or exceeds the permitted use, you will need to obtain permission directly from the copyright holder. To view a copy of this license, visit http://creativecommons. org/licenses/by/4.0/.

\section{References}

1. Nowell PC, Hungerford D. A minute chromosome in human chronic granulocytic leukemia. Science. 1960;132:1497.

2. O'Hare T, Zabriskie MS, Eiring AM, Deininger MW. Pushing the limits of targeted therapy in chronic myeloid leukaemia. Nat Rev Cancer. 2012;12:513-26.

3. Chen Y, Wang H, Kantarjian H, Cortes J. Trends in chronic myeloid leukemia incidence and survival in the United States from 1975 to 2009. Leuk Lymphoma. 2013;54:1411-7.

4. Graham SM, Jorgensen HG, Allan E, Pearson C, Alcorn MJ, Richmond L, et al. Primitive, quiescent, Philadelphia-positive stem cells from patients with chronic myeloid leukemia are insensitive to STI571 in vitro. Blood. 2002;99:319-25.

5. Corbin AS, Agarwal A, Loriaux M, Cortes J, Deininger MW, Druker BJ. Human chronic myeloid leukemia stem cells are insensitive to imatinib despite inhibition of BCR-ABL activity. J Clin Investig. 2011;121:396-409.

6. Hamilton A, Helgason GV, Schemionek M, Zhang B, Myssina S, Allan EK, et al. Chronic myeloid leukemia stem cells are not dependent on Bcr-Abl kinase activity for their survival. Blood. 2012;119:1501-10.

7. Bencomo-Alvarez AE, Rubio AJ, Gonzalez MA, Eiring AM. Energy metabolism and drug response in myeloid leukaemic stem cells. Br J Haematol. 2019;186:524-37.

8. Mahon FX, Rea D, Guilhot J, Guilhot F, Huguet F, Nicolini F, et al. Discontinuation of imatinib in patients with chronic myeloid leukaemia who have maintained complete molecular remission for at least 2 years: the prospective, multicentre Stop Imatinib (STIM) trial. Lancet Oncol. 2010;11:1029-35.

9. Rousselot P, Charbonnier A, Cony-Makhoul P, Agape P, Nicolini FE, Varet B, et al. Loss of major molecular response as a trigger for restarting tyrosine kinase inhibitor therapy in patients with chronic-phase chronic myelogenous leukemia who have stopped imatinib after durable undetectable disease. J Clin Oncol. 2014;32:424-30.

10. Bocchia M, Sicuranza A, Abruzzese E, Iurlo A, Sirianni S, Gozzini A, et al. Residual peripheral blood CD26(+) leukemic stem cells in chronic myeloid leukemia patients during TKI therapy and during treatment-free remission. Front Oncol. 2018;8:194.

11. Chomel JC, Bonnet ML, Sorel N, Bertrand A, Meunier MC, Fichelson S, et al. Leukemic stem cell persistence in chronic 
myeloid leukemia patients with sustained undetectable molecular residual disease. Blood. 2011;118:3657-60.

12. Chu S, McDonald T, Lin A, Chakraborty S, Huang Q, Snyder DS, et al. Persistence of leukemia stem cells in chronic myelogenous leukemia patients in prolonged remission with imatinib treatment. Blood. 2011;118:5565-72.

13. Aichberger KJ, Herndlhofer S, Schernthaner GH, Schillinger M, Mitterbauer-Hohendanner G, Sillaber C, et al. Progressive peripheral arterial occlusive disease and other vascular events during nilotinib therapy in CML. Am J Hematol. 2011;86:533-9.

14. Minson AG, Cummins K, Fox L, Costello B, Yeung D, Cleary R, et al. The natural history of vascular and other complications in patients treated with nilotinib for chronic myeloid leukemia. Blood Adv. 2019;3:1084-91.

15. Caocci G, Mulas O, Abruzzese E, Luciano L, Iurlo A, Attolico I, et al. Arterial occlusive events in chronic myeloid leukemia patients treated with ponatinib in the real-life practice are predicted by the Systematic Coronary Risk Evaluation (SCORE) chart. Hematol Oncol. 2019;37:296-302.

16. Jain P, Kantarjian H, Boddu PC, Nogueras-Gonzalez GM, Verstovsek S, Garcia-Manero G, et al. Analysis of cardiovascular and arteriothrombotic adverse events in chronic-phase CML patients after frontline TKIs. Blood Adv. 2019;3:851-61.

17. Janssen L, Frambach S, Allard NAE, Hopman MTE, Schirris TJJ, Voermans NC, et al. Skeletal muscle toxicity associated with tyrosine kinase inhibitor therapy in patients with chronic myeloid leukemia. Leukemia. 2019;33:2116-20.

18. Gorre ME, Mohammed M, Ellwood K, Hsu N, Paquette R, Rao PN, et al. Clinical resistance to STI-571 cancer therapy caused by BCRABL gene mutation or amplification. Science. 2001;293:876-80.

19. Eiring AM, Page BD, Kraft IL, Mason CC, Vellore NA, Resetca D, et al. Combined STAT3 and BCR-ABL1 inhibition induces synthetic lethality in therapy-resistant chronic myeloid leukemia. Leukemia. 2015;29:586-97.

20. Eiring AM, Kraft IL, Page BD, O'Hare T, Gunning PT, Deininger MW. STAT3 as a mediator of BCR-ABL1-independent resistance in chronic myeloid leukemia. Leuk Suppl. 2014;3 Suppl 1:S5-6.

21. Eiring AM, Khorashad JS, Anderson DJ, Yu F, Redwine HM, Mason $\mathrm{CC}$, et al. $\beta$-catenin is required for intrinsic but not extrinsic BCR-ABL1 kinase-independent resistance to tyrosine kinase inhibitors in chronic myeloid leukemia. Leukemia. 2015;29:2328-37.

22. Carra G, Torti D, Crivellaro S, Panuzzo C, Taulli R, Cilloni D, et al. The BCR-ABL/NF-kappaB signal transduction network: a long lasting relationship in Philadelphia positive leukemias. Oncotarget. 2016;7:66287-98.

23. Breccia M, Alimena G. NF-kappaB as a potential therapeutic target in myelodysplastic syndromes and acute myeloid leukemia. Expert Opin Ther Targets. 2010;14:1157-76.

24. Braun T, Carvalho G, Fabre C, Grosjean J, Fenaux P, Kroemer G. Targeting NF-kappaB in hematologic malignancies. Cell Death Differ. 2006;13:748-58.

25. Chen J, Chen ZJ. Regulation of NF-kappaB by ubiquitination. Curr Opin Immunol. 2013;25:4-12.

26. Vallabhapurapu S, Karin M. Regulation and function of NFkappaB transcription factors in the immune system. Annu Rev Immunol. 2009;27:693-733.

27. McWeeney SK, Pemberton LC, Loriaux MM, Vartanian K, Willis $\mathrm{SG}$, Yochum $\mathrm{G}$, et al. A gene expression signature of CD34+ cells to predict major cytogenetic response in chronic-phase chronic myeloid leukemia patients treated with imatinib. Blood. 2010;115:315-25.

28. Radich JP, Dai H, Mao M, Oehler V, Schelter J, Druker B, et al. Gene expression changes associated with progression and response in chronic myeloid leukemia. Proc Natl Acad Sci USA. 2006;103:2794-9.
29. Khorashad JS, Eiring AM, Mason CC, Gantz KC, Bowler AD, Redwine HM, et al. shRNA library screening identifies nucleocytoplasmic transport as a mediator of BCR-ABL1 kinase-independent resistance. Blood. 2015;125:1772-81.

30. Okumura T, Ikeda K, Ujihira T, Okamoto K, Horie-Inoue K, Takeda S, et al. Proteasome 26S subunit PSMD1 regulates breast cancer cell growth through p53 protein degradation. J Biochem. 2018;163:19-29.

31. Fararjeh AS, Chen LC, Ho YS, Cheng TC, Liu YR, Chang HL, et al. Proteasome 26S subunit, non-ATPase 3 (PSMD3) regulates breast cancer by stabilizing HER2 from degradation. Cancers. 2019;11:527. https://pubmed.ncbi.nlm.nih.gov/31013812/.

32. Dai YJ, Hu F, He SY, Wang YY. Epigenetic landscape analysis of lncRNAs in acute myeloid leukemia with DNMT3A mutations. Ann Transl Med. 2020;8:318.

33. ENCODE Project Consortium. An integrated encyclopedia of DNA elements in the human genome. Nature. 2012;489:57-74. https://pubmed.ncbi.nlm.nih.gov/22955616/.

34. Gerstein MB, Kundaje A, Hariharan M, Landt SG, Yan KK, Cheng $\mathrm{C}$, et al. Architecture of the human regulatory network derived from ENCODE data. Nature. 2012;489:91-100.

35. Fukuoka M, Yoshioka K, Hohjoh H. NF-kappaB activation is an early event of changes in gene regulation for acquiring drug resistance in human adenocarcinoma PC-9 cells. PLoS ONE. 2018;13:e201796.

36. Zhang T, Zheng C, Hou K, Wang J, Zhang Y, Fan Y, et al. Suppressed expression of Cbl-b by NF-kappaB mediates icotinib resistance in EGFR-mutant non-small-cell lung cancer. Cell Biol Int. 2019;43:98-107.

37. Feng PH, Yu CT, Chen KY, Luo CS, Wu SM, Liu CY, et al. S100A9(+) MDSC and TAM-mediated EGFR-TKI resistance in lung adenocarcinoma: the role of RELB. Oncotarget. 2018;9: 7631-43.

38. Chiu CF, Chang YW, Kuo KT, Shen YS, Liu CY, Yu YH, et al. NF-kappaB-driven suppression of FOXO3a contributes to EGFR mutation-independent gefitinib resistance. Proc Natl Acad Sci USA. 2016;113:E2526-35.

39. Han SH, Kim SH, Kim HJ, Lee Y, Choi SY, Park G, et al. Cobll1 is linked to drug resistance and blastic transformation in chronic myeloid leukemia. Leukemia. 2017;31:1659.

40. Chorzalska A, Ahsan N, Rao RSP, Roder K, Yu X, Morgan J, et al. Overexpression of $\mathrm{Tpl} 2$ is linked to imatinib resistance and activation of MEK-ERK and NF-kappaB pathways in a model of chronic myeloid leukemia. Mol Oncol. 2018;12:630-47.

41. Cilloni D, Messa F, Arruga F, Defilippi I, Morotti A, Messa E, et al. The NF-kappaB pathway blockade by the IKK inhibitor PS1145 can overcome imatinib resistance. Leukemia. 2006;20:61-7.

42. Lounnas N, Frelin C, Gonthier N, Colosetti P, Sirvent A, Cassuto JP, et al. NF-kappaB inhibition triggers death of imatinib-sensitive and imatinib-resistant chronic myeloid leukemia cells including T315I Bcr-Abl mutants. Int J Cancer. 2009;125:308-17.

43. Lu Z, Jin Y, Chen C, Li J, Cao Q, Pan J. Pristimerin induces apoptosis in imatinib-resistant chronic myelogenous leukemia cells harboring T315I mutation by blocking NF-kappaB signaling and depleting Bcr-Abl. Mol Cancer. 2010;9:112.

44. Wei W, Huang H, Zhao S, Liu W, Liu CX, Chen L, et al. Alantolactone induces apoptosis in chronic myelogenous leukemia sensitive or resistant to imatinib through NF-kappaB inhibition and $\mathrm{Bcr} / \mathrm{Abl}$ protein deletion. Apoptosis. 2013; 18:1060-70.

45. Heaney NB, Pellicano F, Zhang B, Crawford L, Chu S, Kazmi $\mathrm{SM}$, et al. Bortezomib induces apoptosis in primitive chronic myeloid leukemia cells including LTC-IC and NOD/SCID repopulating cells. Blood. 2010;115:2241-50.

46. Santos FP, Kantarjian H, McConkey D, O'Brien S, Faderl S, Borthakur G, et al. Pilot study of bortezomib for patients with 
imatinib-refractory chronic myeloid leukemia in chronic or accelerated phase. Clin Lymphoma Myeloma Leuk. 2011;11:355-60.

47. Styczynski J, Gil L, Czyzewski K, Kolodziej B, Kurylo-Rafinska $\mathrm{B}$, Lewandowski K, et al. Bortezomib has little ex vivo activity in chronic myeloid leukemia: individual tumor response testing comparative study in acute and chronic myeloid leukemia. Contemp Oncol. 2012;16:210-4.

48. Naugler WE, Karin M. NF-kappaB and cancer-identifying targets and mechanisms. Curr Opin Genet Dev. 2008;18:19-26.

49. Srinivasula SM, Ashwell JD. IAPs: what's in a name? Mol Cell. 2008;30:123-35.

50. Giustacchini A, Thongjuea S, Barkas N, Woll PS, Povinelli BJ, Booth CAG, et al. Single-cell transcriptomics uncovers distinct molecular signatures of stem cells in chronic myeloid leukemia. Nat Med. 2017;23:692-702.

51. Gallipoli P, Pellicano F, Morrison H, Laidlaw K, Allan EK, Bhatia $\mathrm{R}$, et al. Autocrine TNF-alpha production supports CML stem and progenitor cell survival and enhances their proliferation. Blood. 2013;122:3335-9.

52. Reynaud D, Pietras E, Barry-Holson K, Mir A, Binnewies M, Jeanne M, et al. IL-6 controls leukemic multipotent progenitor cell fate and contributes to chronic myelogenous leukemia development. Cancer Cell. 2011;20:661-73.

53. Welner RS, Amabile G, Bararia D, Czibere A, Yang H, Zhang H, et al. Treatment of chronic myelogenous leukemia by blocking cytokine alterations found in normal stem and progenitor cells. Cancer Cell. 2015;27:671-81.

54. Zhang B, Ho YW, Huang Q, Maeda T, Lin A, Lee SU, et al. Altered microenvironmental regulation of leukemic and normal stem cells in chronic myelogenous leukemia. Cancer Cell. 2012;21:577-92.

55. Shen N, Liu S, Cui J, Li Q, You Y, Zhong Z, et al. Tumor necrosis factor alpha knockout impaired tumorigenesis in chronic myeloid leukemia cells partly by metabolism modification and miRNA regulation. Onco Targets Ther. 2019;12:2355-64.

56. Zhang B, Chu S, Agarwal P, Campbell VL, Hopcroft L, Jorgensen $\mathrm{HG}$, et al. Inhibition of interleukin-1 signaling enhances elimination of tyrosine kinase inhibitor-treated CML stem cells. Blood. 2016;128:2671-82.

57. Baba T, Naka K, Morishita S, Komatsu N, Hirao A, Mukaida N. MIP-1alpha/CCL3-mediated maintenance of leukemia-initiating cells in the initiation process of chronic myeloid leukemia. J Exp Med. 2013;210:2661-73.

58. Traer E, MacKenzie R, Snead J, Agarwal A, Eiring AM, O’Hare T, et al. Blockade of JAK2-mediated extrinsic survival signals restores sensitivity of CML cells to ABL inhibitors. Leukemia. 2012;26: 1140-3.

59. Mendez-Ferrer S, Bonnet D, Steensma DP, Hasserjian RP, Ghobrial IM, Gribben JG, et al. Bone marrow niches in haematological malignancies. Nat Rev Cancer. 2020;20:285-98.

60. Kagoya Y, Yoshimi A, Kataoka K, Nakagawa M, Kumano K, Arai $\mathrm{S}$, et al. Positive feedback between NF-kappaB and TNFalpha promotes leukemia-initiating cell capacity. J Clin Investig. 2014;124:528-42.

61. Yu Z, Zhang W, Kone BC. Signal transducers and activators of transcription 3 (STAT3) inhibits transcription of the inducible nitric oxide synthase gene by interacting with nuclear factor kappaB. Biochem J. 2002;367:97-105.

62. Yang J, Liao X, Agarwal MK, Barnes L, Auron PE, Stark GR. Unphosphorylated STAT3 accumulates in response to IL-6 and activates transcription by binding to NFkappaB. Genes Dev. 2007;21:1396-408.

63. Lam LT, Wright G, Davis RE, Lenz G, Farinha P, Dang L, et al. Cooperative signaling through the signal transducer and activator of transcription 3 and nuclear factor-\{kappa $\} \mathrm{B}$ pathways in subtypes of diffuse large B-cell lymphoma. Blood. 2008;111:3701-13.

64. Lee H, Herrmann A, Deng JH, Kujawski M, Niu G, Li Z, et al. Persistently activated Stat3 maintains constitutive NF-kappaB activity in tumors. Cancer Cell. 2009;15:283-93.

65. Grivennikov SI, Karin M. Dangerous liaisons: STAT3 and NFkappaB collaboration and crosstalk in cancer. Cytokine Growth Factor Rev. 2010;21:11-9.

66. Han SS, Yun H, Son DJ, Tompkins VS, Peng L, Chung ST, et al. NF-kappaB/STAT3/PI3K signaling crosstalk in iMyc E mu B lymphoma. Mol Cancer. 2010;9:97.

67. Orlova A, Wagner C, de Araujo ED, Bajusz D, Neubauer HA, Herling M. et al. Direct targeting options for STAT3 and STAT5 in cancer. Cancers. 2019;11:1930. https://pubmed.ncbi.nlm.nih. gov/31817042/.

68. Zhang XD, Baladandayuthapani V, Lin H, Mulligan G, Li B, Esseltine DW, et al. Tight junction protein 1 modulates proteasome capacity and proteasome inhibitor sensitivity in multiple myeloma via EGFR/JAK1/STAT3 signaling. Cancer Cell. 2016;29:639-52.

69. Jesenberger V, Jentsch S. Deadly encounter: ubiquitin meets apoptosis. Nat Rev Mol Cell Biol. 2002;3:112-21.

70. Im E, Chung KC. Precise assembly and regulation of $26 \mathrm{~S}$ proteasome and correlation between proteasome dysfunction and neurodegenerative diseases. BMB Rep. 2016;49:459-73.

71. Saccani S, Marazzi I, Beg AA, Natoli G. Degradation of promoter-bound p65/RelA is essential for the prompt termination of the nuclear factor kappaB response. J Exp Med. 2004;200:107-13.

72. Fisher DAC, Malkova O, Engle EK, Miner CA, Fulbright MC, Behbehani GK, et al. Mass cytometry analysis reveals hyperactive NF Kappa B signaling in myelofibrosis and secondary acute myeloid leukemia. Leukemia. 2017;31:1962-74.

73. Tsvetkov P, Sokol E, Jin D, Brune Z, Thiru P, Ghandi M, et al. Suppression of 19S proteasome subunits marks emergence of an altered cell state in diverse cancers. Proc Natl Acad Sci USA. 2017;114:382-7.

74. Warnes GR, Bolker B, Bonebakker L, Gentleman R, Huber W, Liaw A, et al. Package gplots. Available from: https://CRAN.Rproject.org/package $=$ gplots. 2016.

75. Oh B, Kim TY, Min HJ, Kim M, Kang MS, Huh JY, et al. Synergistic killing effect of imatinib and simvastatin on imatinibresistant chronic myelogenous leukemia cells. Anticancer Drugs. 2013;24:20-31.

76. Yamada T, Park CS, Shen Y, Rabin KR, Lacorazza HD. G0S2 inhibits the proliferation of K562 cells by interacting with nucleolin in the cytosol. Leuk Res. 2014;38:210-7.

77. Mootha VK, Lindgren CM, Eriksson KF, Subramanian A, Sihag $\mathrm{S}$, Lehar J, et al. PGC-1alpha-responsive genes involved in oxidative phosphorylation are coordinately downregulated in human diabetes. Nat Genet. 2003;34:267-73.

78. Subramanian A, Tamayo P, Mootha VK, Mukherjee S, Ebert BL, Gillette MA, et al. Gene set enrichment analysis: a knowledgebased approach for interpreting genome-wide expression profiles. Proc Natl Acad Sci USA. 2005;102:15545-50. 